Neurosurg Focus 24 (1):E13, 2008

\title{
Policy on Conflict of Interest
}

\author{
Journal of Neurosurgery Publishing Group
}

\begin{abstract}
Relationships between industry and neurosurgeons engaged in both clinical practice and research have become increasingly complicated due to increased utilization of expensive devices in day-to-day neurosurgical practice. The Journal of Neurosurgery Publishing Group (JNSPG) has always had a policy of demanding open disclosure of any real, potential, or even perceived conflict of interest by authors submitting scientific manuscripts. Recently, the editor-inchief and members of the editorial boards, after much discussion of this issue, decided that this policy of open disclosure should be enhanced and more specifically defined. In addition, we felt that such a policy should be extended to all reviewers of articles submitted for publication to JNSPG journals-both members of the editorial boards and ad hoc reviewers. To clarify, extend, and specify the JNSPG's policy in this respect, the editor and editorial boards developed a task force on "Conflict of Interest." The task force, after considerable discussion with the full editorial boards, developed the following Conflict of Interest policy as well as the forms that submitting authors, editorial board members, and other reviewers are now required to complete. (DOI: 10.3171/FOC/2008/24/1/E13)
\end{abstract}

Roberto C. Heros, M.D.

Chair, JNSPG Task Force on Conflict of Interest

\section{Conflict of Interest Policy}

To ensure the scientific objectivity of articles appearing in the Journal of Neurosurgery, Journal of Neurosurgery: Pediatrics, Journal of Neurosurgery: Spine, and Neurosurgical Focus, the JNS Publishing Group (JPSPG) requires that all authors, editorial board members, topic editors, editors, and outside reviewers disclose any potential or perceived conflict of interest that may exist regarding manuscripts submitted for review. In addition, the JNSPG reserves the right to request a conflict of interest statement from physicians or scientists not listed as authors who have made a substantial contribution to the work (including a statistician or scientific writer) listed in the manuscript's Acknowledgments section.

\section{Definition of Terms}

Authorship: The JNSPG accepts the definition of authorship stated by the International Committee of Medical Journal Editors (ICMJE) in the Uniform Requirements for Manuscripts Submitted to Biomedical Journals: Writing and Editing for Biomedical Publication, specifically: "Authorship credit should be based on 1) substantial contributions to conception and design, or acquisition of data, or analysis and interpretation of data; 2) drafting the article or revising it critically for important intellectual content; and 3) final approval of the version to be published." Detailed information on who should be listed as authors and who should be listed in an Acknowledgments section as contributors can be found at the ICMJE website (http:// www.icmje.org).

Conflict of interest: A situation in which a person has competing loyalties or interests-financial, personal, or professional- that make if difficult to fulfill his or her duties impartially.

Financial conflict of interest: A financial relationship between an individual (and/or his/her immediate family) and a company whose product is mentioned in a submitted manuscript or competes with a product mentioned in that manuscript. Such a company includes, but is not limited to, manufacturers of biomedical devices or equipment, pharmaceutical companies, and other companies involved in any aspect of health care. Types of financial relationships include ownership, employment, consultant status, and direct stock ownership among others.

Personal conflict of interest: A friendship or rivalry that could influence an individual in the impartial assessment of another's work.

Professional conflict of interest: A professional relationship that could influence an individual in the impartial assessment of another's work.

Contributor: Person who has contributed to the study and/or manuscript but does not meet the criteria for authorship. This person's name and contribution should be included in the Acknowledgments section.

\section{Authors}

Clinical and basic research studies are often financially supported by grants or contracts from federal agencies, nonprofit organizations, or commercial entities. This support may take the form of money or an in-kind contribution. If authors received support for their study and/or the 
reporting of their study, they must clearly identify what support was given and by whom.

If support was received for the study, the corresponding author must state in writing that he or she had full access to all data in the study, takes complete responsibility for the integrity of the data and the accuracy of the data analysis, and exerted complete freedom and independence in the decision to publish the results of the study. At least one independent observer (with no conflict of interest) who has reviewed the data and results should be listed as an author or in the Acknowledgments section. If listed in the latter, the corresponding author should specify this in a note to the editor. If a clinical study has been supported by an external source, the investigators should disclose this fact to the study participants and should state in the manuscript whether this action was taken.

On submission of a manuscript to the JNSPG, all authors must complete and sign an Author's Conflict of Interest Statement and include a Disclosure section in the manuscript. If no conflict of interest exists or is specified, a Disclaimer section will be added to the manuscript with the following statement: "The authors do not report any conflict of interest concerning the materials or methods used in this study or the findings specified in this paper." Authors should be specific about money or in-kind contributions they have received from sponsors. If an employee of the sponsor aided in the study (research design, execution, analysis, or write-up), their participation should be clearly stated by granting authorship or listing the person and level of participation in the Acknowledgments section of the manuscript.

\section{Editorial Board Member/Neurosurgical Focus Topic Editor}

Editorial board members and topic editors must submit an Editor's Statement of Financial Relations with Biomedical Companies to the editor-in-chief. Editorial board members should submit a new form every year; topic editors should submit a form when they agree to serve as topic editor for a particular issue. If editorial board members/topic editors are assigned a manuscript that presents a potential or perceived conflict of interest, they should discuss the matter with their editorial board chair and/or recuse themselves from reviewing the manuscript if appropriate.

\section{Outside Reviewer}

Occasionally, outside specialists are asked to review a manuscript. Outside reviewers should review the JNSPG Policy on Conflict of Interest. If they have a potential or perceived conflict of interest in the impartial assessment of a particular manuscript, they should discuss the matter with the editorial board chair or editor-in-chief and/or recuse themselves from reviewing the manuscript if appropriate.

\section{Editor-in-Chief/Associate Editor}

Each year the editors must submit an Editor's Statement of Financial Relations with Biomedical Companies to be kept on file. If editors encounter a manuscript that could present a potential or perceived conflict of interest, they should recuse themselves from evaluating the manuscript and reassign a nonconflicted reviewer to replace them. 